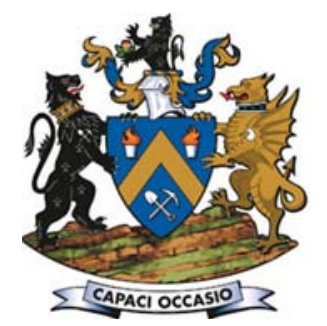

\title{
Application of the event chain project management methodology to a mining stope
}

\author{
by P. Nelwamondo* and J.H.C. Pretorius*
}

\section{Synopsis}

Although South Africa possesses more than $80 \%$ of the world's platinum reserves, its reputation for reliability in supplying platinum to global markets is under threat. This is due to the $49 \%$ decrease in output per worker (1999-2014), while the domestic costs have risen by more than $10 \%$ annually for the past 5 years. In addition, the continued decline in the commodity price by $38.3 \%$ (2012-2016) has resulted in a significant portion of the sector producing at a loss in 2015. The Chamber of Mines (now the Minerals Council of South Africa) has suggested that solutions to improve productivity and reduce cost pressures are required. This research aims to provide operational excellence through the application of event chain project management (ECPM) to improve productivity and reduce operational costs. A case study was used to carry out research in platinum mines, with data collected using a motion-time study to measure the current efficiency of operations in each mining stope through actual activity durations. The results indicate that through the application of the event chain project management methodology, risks affecting the mining stope schedule can be managed, the efficiency of operations was improved by reducing the time spent on each activity, productivity was increased by shortening the project duration, and operational costs were reduced in the process.

Keywords

event chain project management methodology, productivity, mining stope, risks, uncertainty. suggested, among others, the need for solutions to improve productivity and reduce cost pressures. The implementation of these solutions will ensure that the PGM industry thrives and reaches its potential of growing production to more than $322 \mathrm{t}$ by 2020 (Baxter, 2016).

\section{A mining stope}

The study area is an underground mining stope where PGM-bearing ore is extracted using conventional drilling and blasting methods. The PGMs in the Bushveld Complex are found in three distinct reefs - the Merensky, UG2, and Platreef, which are shallow-dipping at about $9^{\circ}, 25^{\circ}$, and $10^{\circ}$ respectively. These orebodies are regarded as narrow tabular reefs due to their low thickness, which is usually less than $1 \mathrm{~m}$. The preferred method of extraction is conventional mining (Musingwini et al., 2009). A conventional underground mining stope is an excavation made for extracting the ore, and as a project it has sequential daily activities linked together to achieve a blast. The activities in a mining stope are characterized by deadlines, start and finish times, and resources are required in order to achieve the daily objective. In most projects, the daily activities are usually unrecognized due to their small size, repetitiveness, and continuity (Mokoena et al., 2013). Although the conventional mining method may be the most prevalent in narrow tabular orebodies, it does have its own set of challenges, including low productivity. Productivity is the effectiveness of the input effort as measured in terms of the rate of output; and is a measure of the extent to which a certain output is obtained from a given input. However, in operations it is highly affected by operational deficiencies, regarded as internal factors.

* University of Johannesburg, South Africa.

(c) The Southern African Institute of Mining and Metallurgy, 2018. ISSN 2225-6253. Paper received Jul. 2017; revised paper received Apr. 2018. 


\section{Application of the event chain project management methodology to a mining stope}

One of the powerful tools used to increase operational productivity is work study, which entails a systematic examination of the methods used to carry out activities in order to improve the effective use of resources and to set up standards of performance for the activities. Work study aims to examine the way in which an activity is carried out; it simplifies and modifies the operational method so that a standard time for performing that activity is set. It embraces techniques such as method study and work measurement. Method study is the systematic recording and critical examination of ways of doing things in order to make improvements; and work measurement is the application of techniques designed to establish the time for a qualified worker to carry out a task at a defined rate of working. When these techniques are applied to study the work in an operation, productivity will increase. Work study helps to achieve a smooth production flow with minimum interruptions, and reduce the cost of operation by eliminating wastage of time and resources (Kanawaty, 1992). However, work study as an operational management tool cannot deal with risks and uncertainties in mining operations. The mining industry requires a tool that will buffer against the uncertainties inherent in the business due to its operational nature.

\section{Risks in a mining stope}

Operations in a mining stope are characterized by internal risks due to their nature. Internal risks are all the occurrences that a project team can control or influence. They take the form of time, cost, scope changes, inexperienced people, staffing, materials, and equipment. Time as a risk in a mining stope project originates from the finite shift duration allocated for the completion of all activities required to achieve a blast. Any change in project scope constitutes a risk because of the limited time available for project completion. Team members' availability increases the chances of project success; however, absenteeism, annual leave, and lack of the skill or experience required to execute the activity are common risks associated with members in project teams. The availability of resources and equipment required to carry out project activities is a common risk in a stope. These risks have potential to affect the planned project duration, leading to delays in activities and ultimately in the project. According to Razaque et al. (2012), there is a relationship between existing risks residing in the project and related activity time. Therefore, the significant way to manage risks in a project is to understand their effects on the project schedule, in order to estimate a reliable project schedule (Razaque et al., 2012). Patrick and Warchalowski (2013) further state that every organization can achieve competitive advantage by completing projects sooner. This competitive advantage comes through fast realization of project benefits, and the fast delivery of projects with the same resources lowers the overall costs per project.

Phillis and Gumede (2009) suggested that a stope could equate to a micro-project due to its concurrent activities that require precise execution with limited resources within a finite shift duration. A stope falls within the field of project management due to the inherent risks and uncertainties, which increases the risk of project failure. These risks are discrete occurrences that may affect the project in an adverse way, and uncertainties are uncommon states of nature characterized by the absence of any information related to a desired outcome (William, 2004). Koleczko (2012) suggests that management of risks and uncertainties is the fundamental principle of project management's role. Furthermore, Virine and Trumper (2017) insist that project management is the art of analysing and managing risks; without risks there is little need for project management. Project management is extremely flexible and can be adapted to any project; its strength focused on adaptation to difference project needs, including risky projects (Malczyk, 2011). Strauss (2016) contemplated that the application of project management principles within the operational environment ('operational project management') could contribute significantly to the sustainability and competitiveness of a platinum mine. In addition, the suggestion by Moorosi (2010), that project management best practices can be used to contain costs and increase production in a gold mine, gives effect to the use of project management as a tool to improve productivity in all mines due to the similar characteristics. According to Munns (1996), project management is more efficient than traditional functional management methods, especially in complex environments.

\section{Literature review}

A case study (Phillis and Gumede, 2009) was conducted previously of the application of a project management methodology, the critical chain project management (CCPM) methodology, in a platinum mine. The CCPM is aimed at planning; executing, and managing projects and emphasizes the availability of resources (people, equipment, physical space) required to execute project tasks. Goldratt (2007) developed CCPM in response to many projects being dogged by poor performance manifesting in longer than expected durations, frequently missed deadlines, increased costs in excess of budget, and substantially less deliverables than originally promised. The steps that led to the selection of this methodology for application in a mining stope were not defined in the case study; however, there was visible improvement in productivity following the application (Phillis and Gumede, 2009). The successful application of CCPM at the platinum mine was, however, short-lived. A mine official stated in an interview that 'the application was stopped as the methodology had challenges'. A literature review on the CCPM revealed that the application of the methodology leads to organizational change, including the way workers fulfil their work. A study done by Verhoef (2014) for general projects on "what causes project workers to resist working according to the principle of critical chain project management' confirmed that there is clear resistance from workers to fully adapt to the methodology. Furthermore, workers find it hard to disassociate from traditional principles and, to some extent, they appear to easily fall back to old patterns. Resistance to change is a natural and normal human response. The study further states that, the implementation of the methodology often goes reasonably well; however, there are worries concerning long-term sustainability, and currently there is no literature that shows evidence of long-term sustained success of the methodology. In a traditional industry like mining, there is limited flexibility to accommodate drastic changes in operational 


\section{Application of the event chain project management methodology to a mining stope}

activities such as those brought about by the CCPM. Consideration of available methodologies led to the selection of ECPM based on its capability to deal with risks and uncertainties, and its flexibility to serve complex projects

\section{Event chain project management methodology}

ECPM is an uncertainty modelling technique that schedules network analysis for project management. It focuses on the identification and management of events that may affect projects, as it stems from a notion that all projects entail multiple risks. These risks are termed 'events' in the application of this methodology. These events are difficult to identify and analyse, which often leads to inaccurate scheduling. ECPM is the next advanced methodology beyond the critical path method and critical chain project management (Jat, 2016). This was confirmed by Pranam (2014), who compared ECPM with the critical path method in a study of the construction industry. ECPM was found to have a schedule performance index $10.95 \%$ better than the critical path. Furthermore, it was found to be more effective as it provides a structured approach to identifying risks and to estimating a schedule that consider these risks. The methodology mitigates against negative impacts of motivational and cognitive biases that lead to 'best scenario' planning, which is often not achievable and results in inaccurate planning. It focuses on events rather than continuous process problems, as events can be ameliorated before they affect the project to a significant extent. Furthermore, ECPM insists that understanding of the relationship between the project and the events will influence actions to protect the project against such events. These actions involve the application of ECPM principles. These are:

1. The moment of event and excitation

2. The event chain

3. The event diagram

4. Risk analysis

5. Risk quantification

6. Performance measurement.

(Virine and Trumper, 2011).

\section{Problem statement}

The platinum mine where the study was conducted has reduced its estimated production outlook for 2017 to 710000 platinum ounces from the initial plan of 750000 ounces. This will affect the production guidance of 830000 ounces building up to 2020 . The reduction was due to a $35 \%$ deterioration in productivity from an average face advance of $17 \mathrm{~m}$ per month in 2009 to $11 \mathrm{~m}$ per month in 2016, which is $15 \%$ less than the current targeted average face advance per month of $13 \mathrm{~m}$. There are many external factors which contribute to this deterioration in production, including frequent issuing of Section 54 stoppages, underground fires, and fall of ground incidents. However, the company seeks to improve efficiency through operational excellence strategies that will improve productivity regardless of external factors.

\section{Research objective}

This research aims to instil operational excellence by improving efficiency in a mining stope, through the application of the ECPM methodology, which will:
> Manage internal risks in a mining stope affecting the mining stope schedule

> Improve the efficiency of operations by reducing the time spent on each activity

- Improve productivity by reducing the duration of the project

> Reduce operational costs

- Be a pilot for all other platinum mines with similar conditions.

\section{Research methodology}

This case study research was carried out using the following methods:

> Both qualitative and quantitative methods were used in data collection and analysis, through complementary triangulation.

> The data was collected at a platinum mine consisting of a complex with 13 shafts; five mining stopes were selected from four shafts - no. 1, 10,12, and 14 .

> The collection methods used were observations through a motion-time study, and questions directed at team members to add explanation to the observations.

> The observations were carried out using a stopwatch to measure the amount of time spent in completing each activity. Start and finish durations were recorded for each process involved in a mining cycle.

> The observers were mining engineering graduates; they proceeded underground at the beginning of each shift and exited with the miner of the panel. This was done continuously for 12 shifts, and all times were recorded on a checklist, together with any source of delays and disruptions.

\section{Results and analysis}

The project has a planned schedule of 8 hours and 30 minutes (08:30:00), termed 'best practice'. Figure 1 Planned vs actual durations, which include all the activities involved to achieve the objective in the five stopes studied, with the best practice. There are obvious discrepancies between the planned schedule and the actual project schedule for the five stopes, with only one panel achieving an actual project duration close to that planned. This is attributed to fewer events experienced at that working place. The remaining four panels took on average of $32 \%$ more time than planned. These results indicate failure of the project to complete on the planned schedule. The factors contributing to this state of affairs were investigated further earch. The event chain methodology was used to identify and manage events affecting the project schedule.

\section{Application of the first principle of ECPM}

The first principle of ECPM is derived from the field of quantum mechanics; it explains the behaviour of matter in response to a force applied. In a project, when a force in a form of an event acts on an activity, the activity responds by changing its form from the ground state to the excited state. The ground state is the original or planned state of the activity, while the excited state is the new state. The results presented in the Appendix (Figures 9-13) indicate the best practise (blue bars), which represents the planned durations in a ground state, while the red bars represents the actual duration of each activity in an excited state. 


\section{Application of the event chain project management methodology to a mining stope}

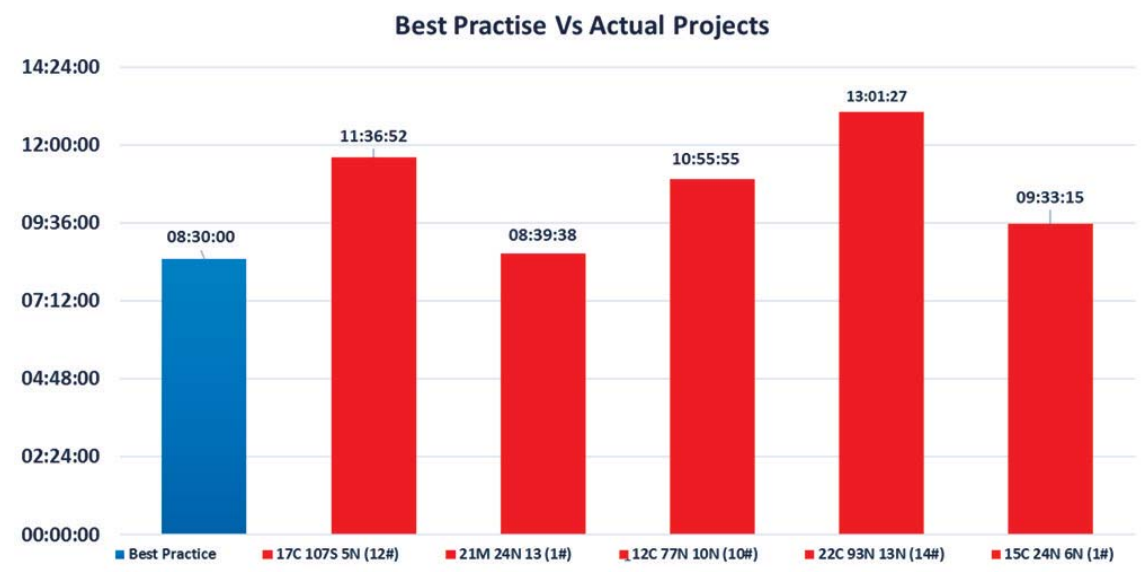

Figure 1-Planned vs actual durations

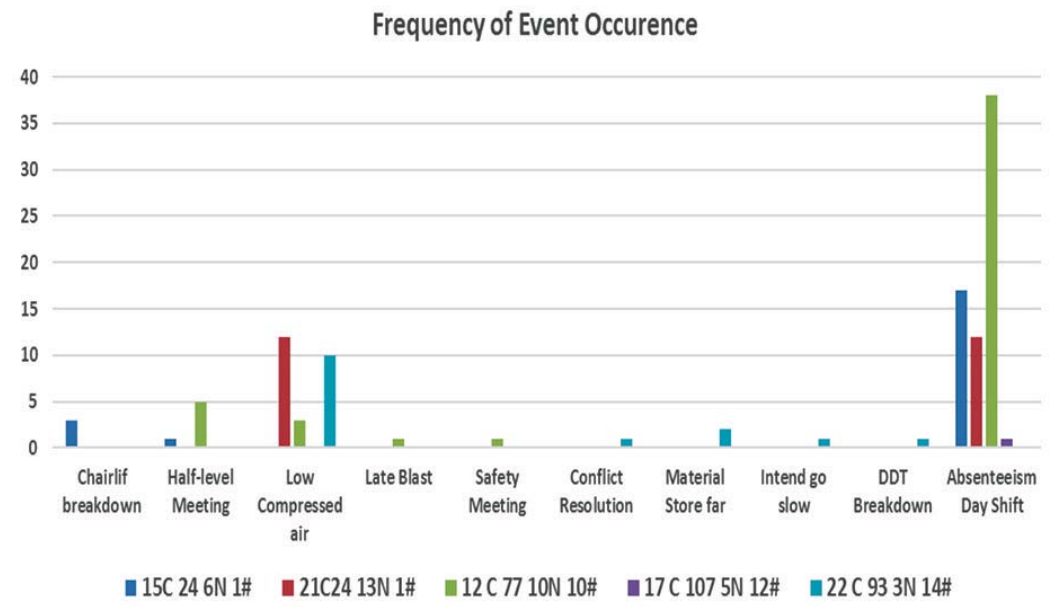

Figure 2-Frequency of event occurrence

The activities 'travelling in' and 'travelling out' span from the time spent waiting for the cage until arrival at the destination. The durations recorded for all working places ranges from 00:30:00 to 00:57:00 (hours: minutes: seconds), which is higher than the 00:30:00 stipulated by the planned schedule. This indicates delays in the arrival of the cage, and slow walking to the waiting place.

The activity 'entry examination', which commences from the waiting place to the panel; indicates a range of 00:41:00 to $01: 51: 00$, this is lower that the planned 01:30:00, however, there are pertinent questions to be asked about the panels that spend only 00:26:00 and 00:41:00 on this activity. These results indicate non-adherence to the procedure for carrying out this activity; some of the steps are being skipped in order to have more time for production activities.

The activity 'temporary support and face preparation' ranges from 00:25:00 to 01:18:00, while the planned duration is 02:30:00. This is a serious concern, since all panels managed to complete this activity in just $51 \%$ or less of the stipulated time. These results again indicate that the procedure for carrying out this activity is not followed properly.
The activity 'drilling' for all working places range from 03:15:00 to 05:17:00, which is higher than the planned 03:00:00. The minimum recorded time of 03:15:00 is acceptable, but the highest time of 05:17:00 indicates a problem that is affecting all working places

The activity 'explosives' is a combination of charging and connecting up. The duration ranges from 01:25:00 to 03:25:00, while the planned time is 01:30:00. The minimum recorded time of 01:25:00 is acceptable, but the highest recorded time of 03:25:00 indicates delays.

\section{Application of the second principle of ECPM}

The second principle of ECPM is concerned with the occurrence of any event within a project which has potential to trigger further events, forming an event chain. The events identified are indicated in Figure 2: absenteeism, low compressed air, and half-level meeting; the 'low compressed air' being attributed to the common technology of pneumatic drills powered by compressed air.

The half-level meeting, safety meeting, conflict resolution, and intentional go-slows represent differences within a team and the time that the team spent trying to settle them. Conflicts are a common phenomenon when humans are working together to achieve a goal; the meetings 


\section{Application of the event chain project management methodology to a mining stope}

are platforms to resolve these conflict. Chairlift breakdown and DDT breakdown events are seen to affect only two specific working places; this is because only one working place uses chairlifts for travelling, and only one working place uses the DDT for the installation of roofbolts. The 'late blast' and 'far material store' also affect only one particular working place each. These events have resulted in activity delays, and ultimately project delays. This has resulted in discrepancies between the planned project schedule and the actual durations.

\section{The application of the third principle of ECPM}

The third principle illustrates the complex relationships between the events and the project, in a diagrammatic form for all stakeholders to see. Due to the complexity of the relationships between the events, the event chain diagram uses the familiar structure of a Gantt chart to visualize the relationships between project events. Figure 3 indicates the relationships between all the events identified and all the activities within the project. These events resulted in deviations from the planned schedule of 08:30:00 to the actual duration of 12:30:00.

\section{Application of the fourth principle of ECPM}

The fourth principle of ECPM is concerned with event analysis, which enables the identification of the critical events. Critical events are events with potential to cause project failure; their identification will ensure that an appropriate response plan is implemented. Through the process of analysis the probability and severity of each event is determined and understood, which enables the ranking of each event.

\section{Probability of event occurrence}

After events are identified, their probability of occurrence should be determined; their ranking of importance regarding potential damage follows this (Munier, 2014). The probability of occurrence is determined using the recorded frequency of occurrence from Equation [1]. The results are shown in Figure 4.

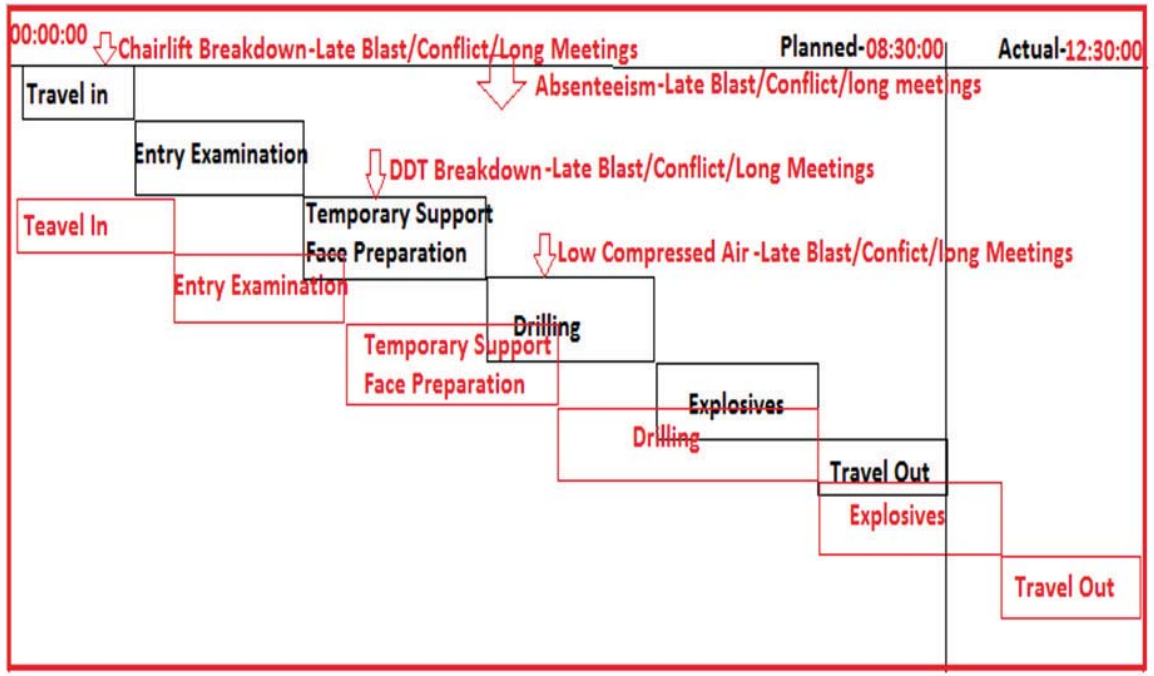

Figure 3-Event chain diagram

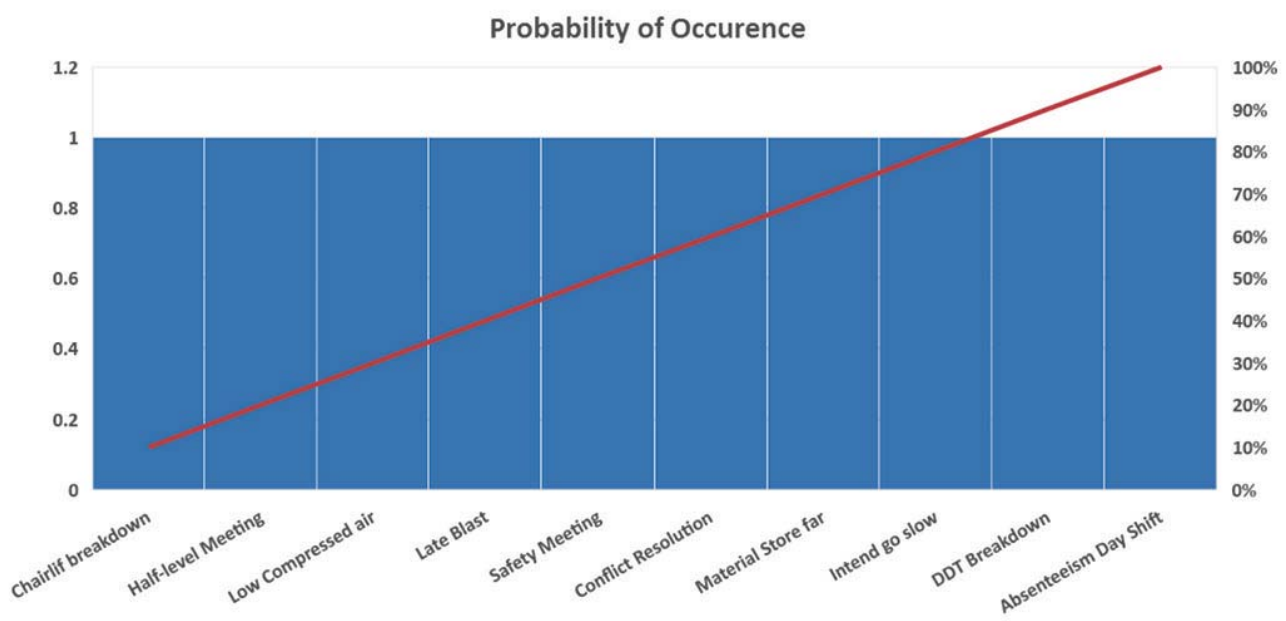




\section{Application of the event chain project management methodology to a mining stope}

$$
\text { Event Ranking }=\text { Probability } * \text { Severity }
$$

\section{Severity of event}

An event, by its very nature, has a negative impact on the project more often than not. However, the magnitude of the impact varies in terms of project duration, cost, or some other critical factor. The severity of impact is determined using a scale of $1-10,1$ being assigned to little impact and 10 indicating a catastrophic impact using (Anon, n.d.). The results are shown in Figure 5.

\section{Event ranking}

Events ranking is a qualitative evaluation used to acquire information about the threat and its performance; often, an event matrix is used (Munier, 2014). However, in this case a ranking formula was used (Equation [2]. Figure 6 shows the ranking of each event based on probability of occurrence and the severity of the impact on the project. Absenteeism, ranked $62 \%$, is considered the most critical event with the highest potential to cause project failure. DDT breakdown ranked at 48\%; making it the second-highest ranked event; it affects drilling and ultimately contributes to project delay. DDT breakdown is followed by low compressed air at $44 \%$, which causes delays in drilling and triggers other events such as a late blast or project failure.

\section{Probability $=$ Number of favourable outcomes \\ Number of possible outcomes}

Once the events have been ranked, a comprehensive mitigation plan can be employed to lower the impact. In this case, absenteeism was identified as the most critical event. Absenteeism refers to the unscheduled absence of employees from the workplace. Since it is unscheduled, precautionary measures cannot be implemented. Absenteeism has potential to hurt the business, due to the drop in production coupled with constant or increasing costs. Absentee employees are a financial burden to the business and a workload burden to other employees. This event forces the team to adjust and stretch their strengths in order to cover the gap; this can have severe consequences for both safety and production (Folger, 2016). According to Gouws (2015), there is a positive relationship between absenteeism and physical workplace conditions; therefore, improved working conditions will discourage absenteeism.

Compressed air is a source of power for the pneumatic drilling machinery. Its efficiency is the lowest compared to other power sources like electricity and hydropower, and the power available decreases with increasing distance due to leakages. However, its versatility has resulted in it being used to power a variety of pneumatic equipment, with the

\section{Event Severity Estimation}

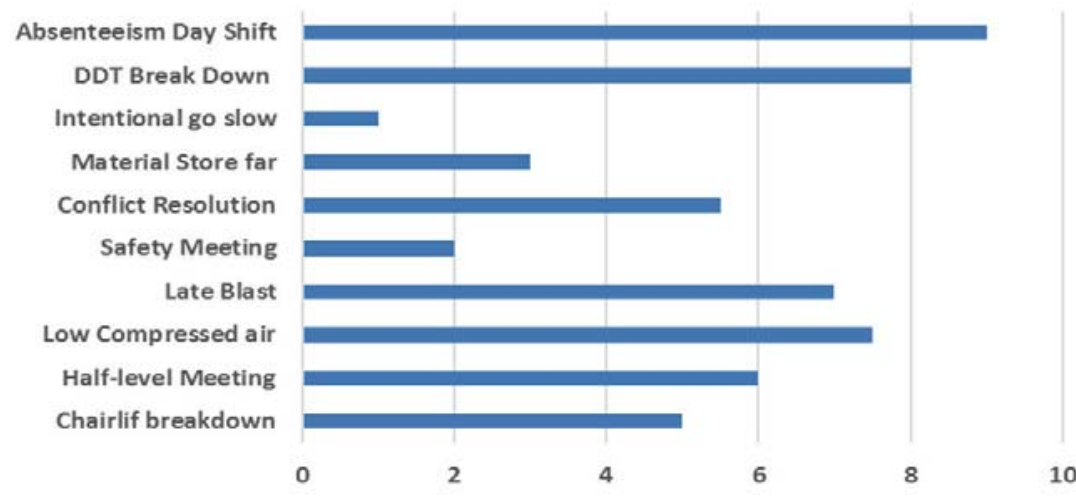

Figure 5-Event severity estimation

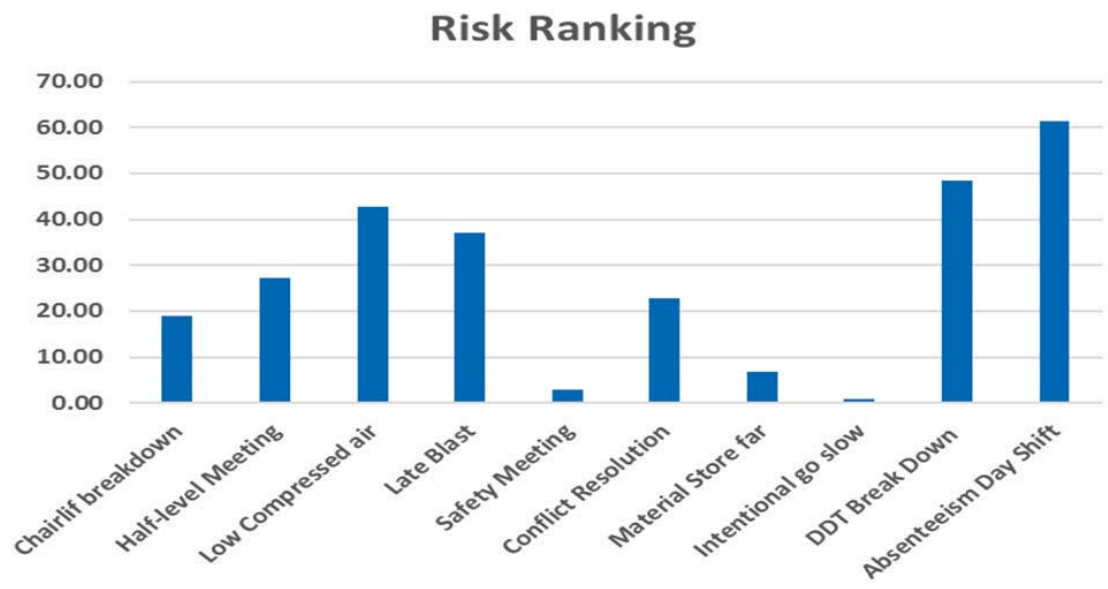




\section{Application of the event chain project management methodology to a mining stope}

result that the supply needs to be shared. According to Hassan et al. (2011), the use of compressed air can be optimized if mines adopt appropriate control philosophies, such as the setting of compressor pressure such that it is allowed to cut back. Drilling is the main activity that utilizes compressed air, therefore during the drilling activity the guide vanes should be fully opened so that the compressors run at full capacity to cover the demand, and they should be closed when drilling ends. Furthermore, a mine with only one compressor must increase the number of compressors when faced with 'low compressed air' challenges.

The breakdowns experienced with DDT machinery and the chairlifts are a failure to function properly or an occurrence in which a machine stops working. According to Kumar and Rudramurthy (2013), breakdowns can be prevented by a good maintenance system, which increases machine availability and productivity; and moreover deals with the root causes of breakdowns

\section{The application of the fifth principle of ECPM}

The fifth principle deals with the quantification of the events. Event quantification is the process of evaluating the critical events and developing data that will be needed for decisionmaking about these events. Furthermore, it measures the cumulative impact of the critical events on the project schedule. Quantification is a quantitative assessment of the value of the events and their effect on the project output. An event may affect a single activity or more than one activity, therefore their effect on the project requires understanding. This will assist in revealing the economic loss or time lost due to the occurrence of critical events; however, this research considers only the impact on the project duration, hence termed 'duration cumulative' $\left(D_{\text {cum }}\right)$ (see Equation [3].

$$
D_{\text {cum }}=\sum_{i=1}^{n}\left(D_{i}^{\prime}-D_{i}\right)^{*} k_{i}
$$

In order to determine the cumulated duration due to the events, a sum of all affected activities in a project is considered, as the cumulated duration results from impacts of all affected activities. The effects on activities in a form of delays are visible when compared to the planned activity durations; however, correlation between each activity's duration and the project duration must be performed so that the event's effect on activities and the whole project is estimated. The correlations were performed using a Spearman's rank-order correlation, represented by $k$ in Equation [3], which is the nonparametric version of the Pearson product-moment correlation; it measures the strength and direction of association between two ranked variables (Laerd Statistics, 2013), in this case the duration of each activity correlated with the project duration. The planned duration for each activity is represented by $D_{i}$, and the actual duration which is affected by an event is represented by $D_{i}$.

The results from the cumulated durations, presented in Figure 7, indicate that the critical events resulted in cumulated durations for several activities. Drilling and explosives activities suffered major delays, as seen from the high percentage of cumulated durations.

The results presented in Figure 8 indicate that through the application of ECPM, the time wasted by the events can be recovered through a comprehensive mitigation plan. According to the results, in panel $22 \mathrm{C} 933 \mathrm{~N}$ 03:28:00 can be recovered, in panel $12 \mathrm{C} 7710 \mathrm{~N} \mathrm{02:45:00}$ can be recovered, in panel $15 \mathrm{C} 246 \mathrm{~N}$ 01:48:00 can be recovered, and in panel $171075 \mathrm{~N}$ 01:50:00 can be recovered.

\section{The application of the sixth principle}

The sixth principle is a critical principle of ECPM, which deals with monitoring of project activities using updated information to perform a new analysis, which can be used to recalculate the probability of events occurring, and the actual impact, and a new project schedule can be generated. In addition, this principle puts more emphasis on ensuring that a comprehensive mitigation plan is employed and is strengthened regularly.

\section{Conclusion and recommendations}

This research has demonstrated that ECPM can be used as a tool to improve productivity in a mining stope. The methodology is capable of dealing with internal risks affecting the planned mining stope schedule; it improved the

IMPACT OF EVENTS ON ACTIVITIES \%

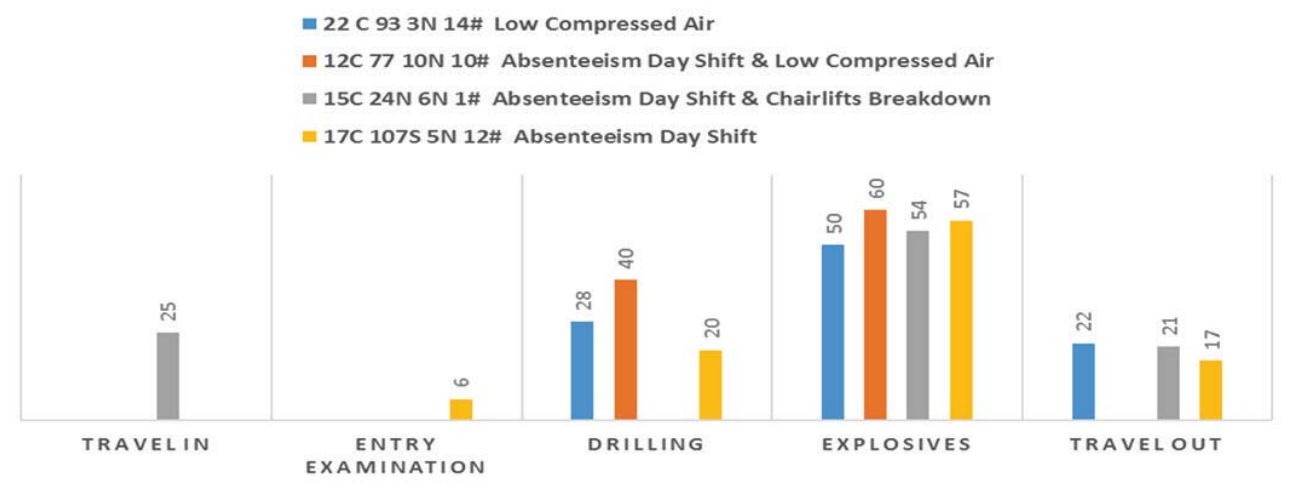

Figure 7-Cumulated duration for each affected activity (\%) 


\section{Application of the event chain project management methodology to a mining stope}

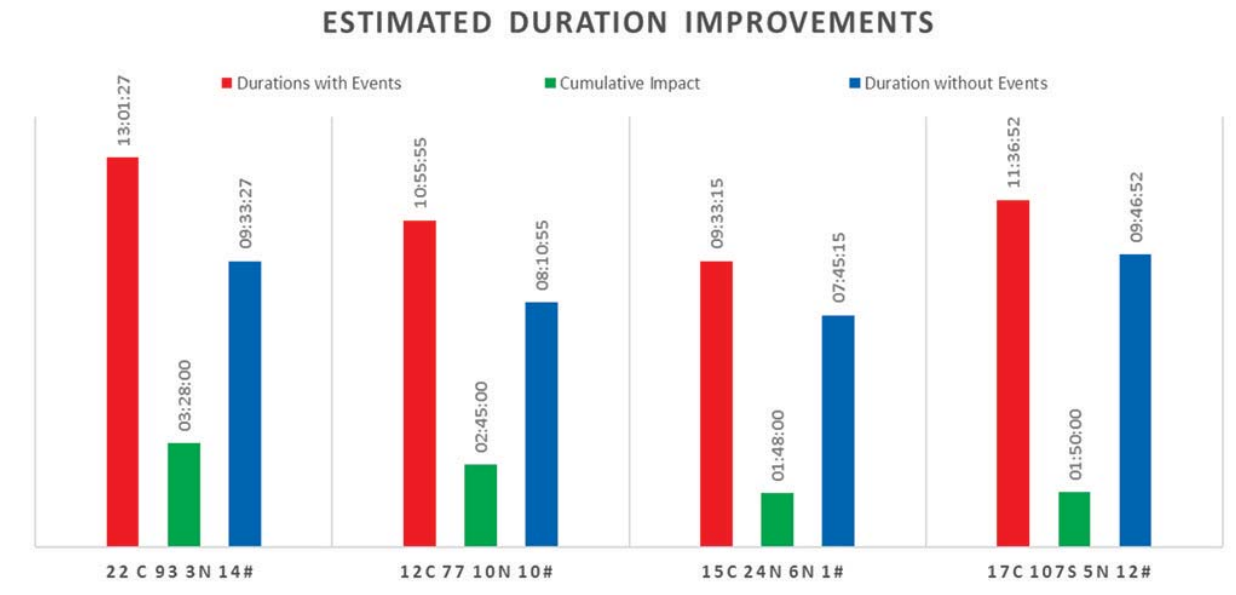

Figure 8-Improved project durations

efficiency of operations by reducing the time spent on each activity. Furthermore, it improved productivity by reducing the project duration.

The presence of risks within an activity reduces the efficiency of carrying out the activity, because of the time wasted in dealing with risks. Elimination of the risks will allow effective use of the allocated time; thus the efficient use of the project duration. However, the improvement in efficiency in this project is limited to project duration, and is not linked to the quality of the product; that constitutes a limitation for this research. Further research should be conducted to test the methodology's ability to improve on the quality of the product or service rendered at a specific duration.

As stated by the triple constraints theory, there are three restrictions in a project. These are scope, time, and costs, and they are interdependent. These three factors are related in a defined and predictable way, because the cost is a function of scope and time; if one changes, then another must change (Baratta, 2006). Therefore, when the project time is reduced, then the costs will decrease.

This research demonstrated the use of project management to break the boundaries created by traditional ways of management; ways that lead professionals to believe that projects and operations run parallel and never link. It research has confirmed that operations can be improved using project management (Joslin and Muller, 2016)

\section{References}

Anon. Not dated. https://www.mindtools.com/pages/article/newPPM_78.htm [accessed 13 June 2017].

BaratTa, A. 2006. The triple constraint, a triple illusion. Proceedings of the PMI Global Congress, Seattle, WA. Project Management Institute, Newtown Square, PA.

BAXTER, R. 2016. The Future of South African Mining. Chamber of Mines South Africa, Johannesburg.

BELLI, G. 2008. Non-experimental quantitative research. Research Essentials: An Introduction to Designs and Practices. Lapan, S.D. and Quartaroli, M.T. (eds.). Wiley. Ch. 4.

Cooper, D., Bosnich, P., Grey, S., Purdy, G., Raymond, G., Walker, P., and Wood, M. 2014. Project Risk Management Guidelines. 2nd edn. Wiley, Chichester, UK.

JAT, D.R. 2016. Project management using event chain methodology. Commerce, vol. 5 , no. 6. p. 1.
FAmily HeAlth InTERnAtionaL. 2016. Qualitative research methods overview. Family Health International. Durham, NC.

FARQUHAR, J.D. and Michels, N. 2016. Triangulation without tears. Markerting Challenges in a Turbulent Business Environment. Groza, M. and Ragland, C. (eds.). Springer, Heidelberg, pp. 325-330.

FoLGER, J. 2016. The causes and costs of absenteeism http://www.investopedia.com/articles/personal-finance/070513/causesand-costs-absenteeism.asp [accessed 21 April 2017].

GOLDRATT, E. 2007. http://goldratt.co.uk/resources/critical_chain/ [accessed 5 October 2016].

Gouws, W.S. 2015. The relationship between absenteeism andphysical workplace conditions at Tshepong mine. MBA dissertation, University of the Free State, Bloemfontein, South Africa.

Hassan, A., Khmaies, O., Twala, B., and Marwala, T. 2011. Optimization of the compressed air-usage in South African Mines. ProceedingS of IEEE Africon, 13-15 September, 2011, Zambia. IEEE. http://hdl.handle.net/10210/16393Herrera, M. 2013. Four types of risk mitigation. https://www.mha-it.com/2013/05/four-types-of-riskmitigation/ [accessed 10 January 2017].

JosLin, R. and MULLER, R. 2016. Relationships between a project management methodology and project success in different project governance. International Journal of Project Management, vol. 33, no. 33. pp. 1377-1392.

KanAWATY, G. 1992. Introduction to Work Study. 4th edn. Skotanville Braamfontein, South Africa.

KoleczKo, K. 2012 Risk and uncertainty in project management decisionmaking. Public Infrastructure Bulletin, vol. 1, issue. 8, article 13.

Kononenko, I. and Kharazil, A. 2014. The methods of selection of the project management methodology. International Journal of Computing, vol. 13, no. 4. pp. 240-247.

KumAR, P. and RUdRAMURTHy. 2013. Analysis of breakdowns and improvement of preventive maintenance on 1000 ton hydraulic press. International Journal of Emerging Technology and Advanced Engineering, vol. 3, no. 8.

MaLczyK, A. 2011. The importance of project management. http://www.bbrief.co.za/resources/articles/the-importance-of-projectmanagement [accessed 24 April 2017].

MAYES, K. 2004. What is quantum mechanics? http://www.thekeyboard.org.uk/ Quantum\%20mechanics.htm [accessed 30 May 2017].

McClinton, C. and Greener, J. 1985. Triangulation in practice. Evaluation and Program Planning, vol. 8. pp. 351-357.

McKAY, D. 2017. Lonmin leaks cash in Q1 as low productivity, absenteeism strike https://www.miningmx.com/top-story/28814-lonmin-loses-moneyq1-low-productivity-absenteeism-strikes/http://www.miningmx.com. [accessed 8 March 2017].

Mndzebele, A.S. 2011. An approach to risk management in the mining projects environment-a case study. MPhil thesis, University of Johannesburg.

Moкoena, T.S., Pretorius, J.H., and Van Wyngaard, C.J. 2013. Triple Constraints Considerations in the Management of Constraints Projects. Bangkok, s.n. 


\section{Application of the event chain project management methodology to a mining stope}

Moorosi, L.F. 2010. The management of high-technology projects. University of South Africa.

MunieR, N. 2014. Risk Management for Engineering Projects Procedures, Methods and Tools. Springer, Spain.

MunNs, A.K. and BJEIRMI, B.F. 1996. The role of project management in achieving project success. International Journal of Project Management, vol. 4 , no. 2. pp. $81-87$.

Musingwinl, C., Ali, M.M. and Dikgale, T. 2009. A linear programming and stochastic analysis of mining replacement rate for typical bushveld complex platinum reef conventional mining under variable geological losses. Johannesburg, South African Institute of Mining and Metallurgy.

OWASP. 2016. OWASP risk rating methodology. https://www.owasp.org/ index.php/OWASP_Risk_Rating_Methodology. [accessed 21 April 2017].

PAtrick, D. and Warchalowski, J. 2013. Gaining competitive advantage through reducing project lead times. Proceedings of the PMI Global Congress, New

Orleans, Louisiana. http://www.cmsmontera.com/wpcontent/uploads/2013/10/Gaining-Competitive-Advantage-through Reducing-Project-Lead-Times-final.pdf

Phillis, R.D. and Gumede, H. 2009. The Impala case study on stoping shift buffering: a critical chain project management perspective. Proceedings of the Hard Rock Safe Safety Conference 2009. Southern African Institute of Mining and Metallurgy, Johannesburg. http://www.saimm.co.za/ Conferences/HardRockSafety2009/031-046_Phillis.pdf

Pranam, B., Madhusudan, G.K, and Sudharshan, K.R. 2014. A comparison study between event chain methodology and critical path method in the construction industry. International Journal of Recent Development in Engineering and Technology, vol. 2, no. 4. www.ijrdet.com/files/Volume2Issue4/IJRDET_0414_14.pdf
ProbabilityFormula. 2017. http://www.probabilityformula.org. [accessed 21 April 2017]

Razaoue, A., Bach, C., Salama, N., and Alotaibi, A. 2012. Fostering project schedule and controlling risk management. International Journal of Business and Social Science, vol. 3, no. 14. https://arxiv.org/pdf/ 1210.2021

Roberts, P. and Priest, H. 2006. Reliability and validity in research. Art and Science, vol. 20, no. 44. pp. 41-45.

Statistics South AfricA. 2016. Mining production and sales. Pretoria.

LAERD STATISTICS. 2013. Spearman's rank-order correlation. https://statistics.laerd.com/statistical-guides/spearmans-rank-ordercorrelation-statistical-guide.php. [accessed 21 April 2017].

StRAuSS, H.. 2016. The argument for operational project management in the South African mining industry. MPhil thesis, University of Johannesburg.

Verhoef, M. 2014. Critical chain project management. Master of Project Management thesis, HU University of Applied Science, Utrecht.

VIRINE, L. and TRUMPER, M. 2011. Event chain methodology in project management. CEPIS Upgrade, vol. XII, no. 5. pp. 22-33. http://www.cepis.org/upgrade/media/trumper_2011_51.pdf

VIrINE, L. and Trumper, M. 2017. Project Risk Analysis Made Ridiculously Simple. World Scientific Publishing, Calgary.

WiLLiam, L. 2004. William, L., 2004, Risk Management, http://isites.nhu.edu.tw/blog/lib/read_attach.php?id=2386

YIN, R.K. 2014. Case Study Research Design and Methods. 5th edn. Sage, Thousand Oaks, CA

ZAINAL, Z. 2007. Case study as a research method. Jurnal Kemanusiaam. https://jurnalkemanusiaan.utm.my/index.php/kemanusiaan/article/downl oad $/ 165 / 158$

\section{Appendix}

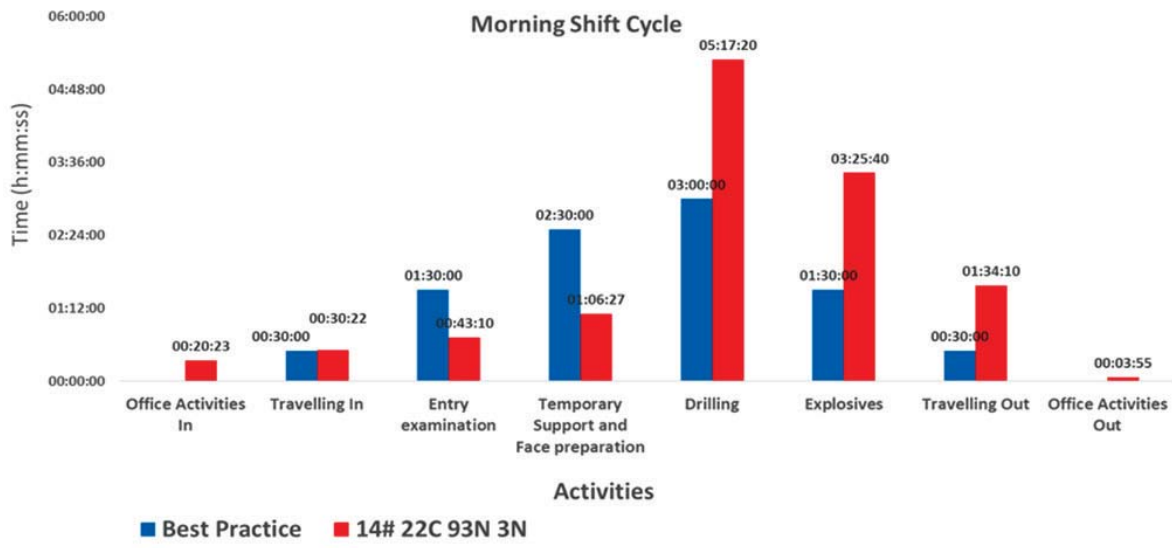

Figure 9-Morning Shift Activities for 22C 93N 3N 14\#

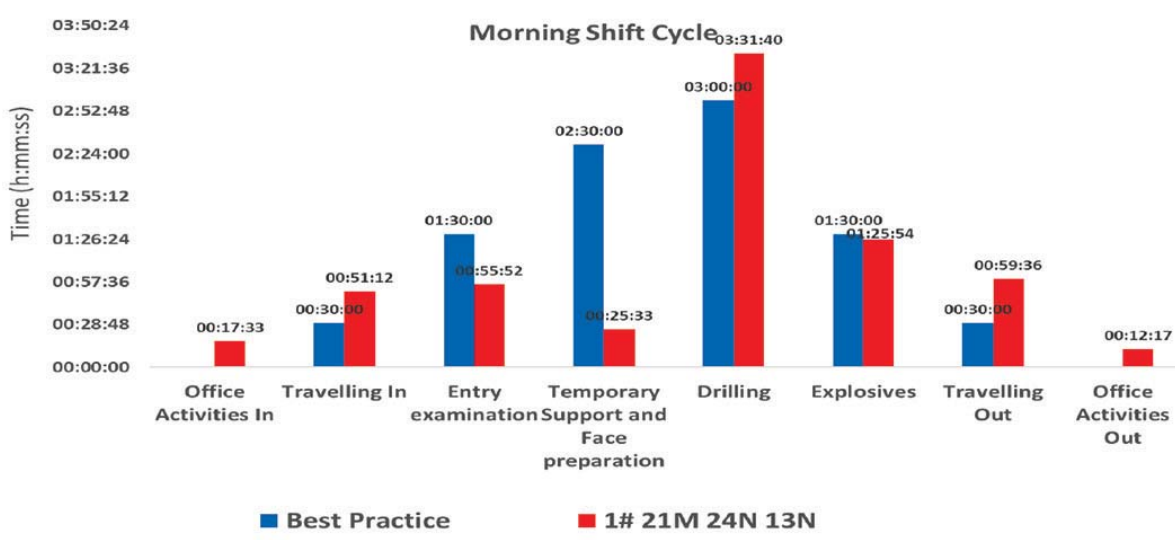

Figure 10-Morning Shift Activities for 21M 24N 13N 1\# 
Application of the event chain project management methodology to a mining stope

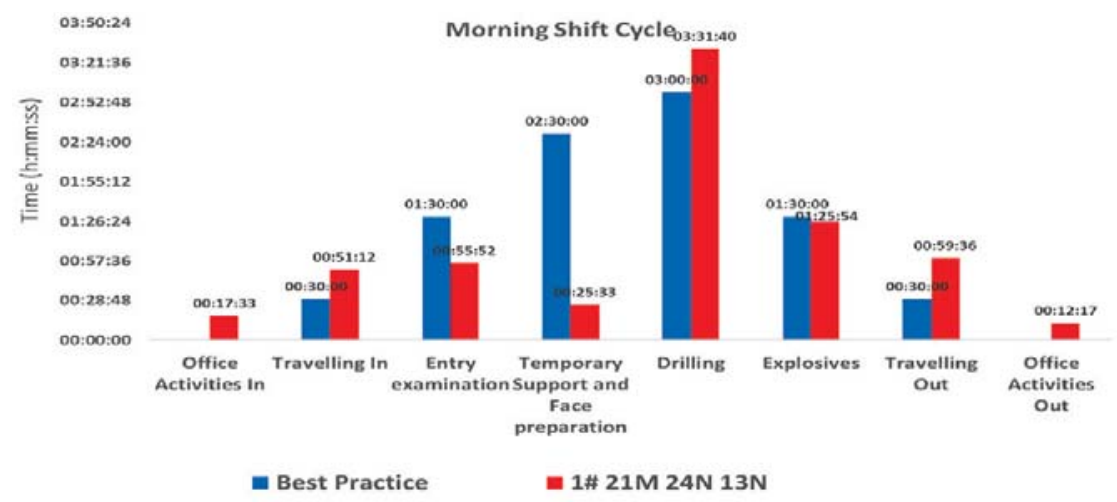

Figure 10-Morning shift activities for 21M 24N 13N 1\#

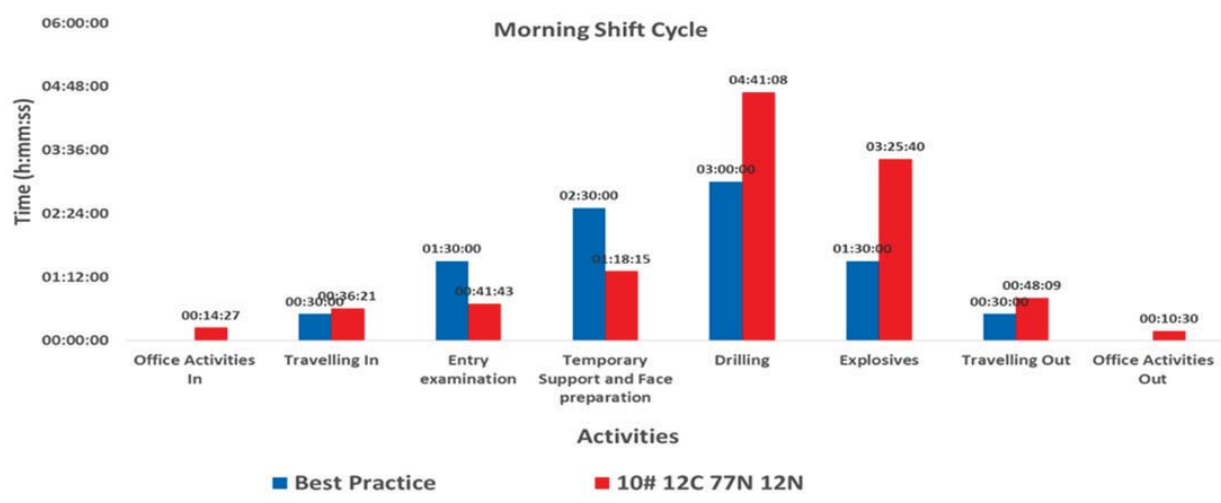

Figure 11-Morning shift activities for 12C 77N 12N 10\#

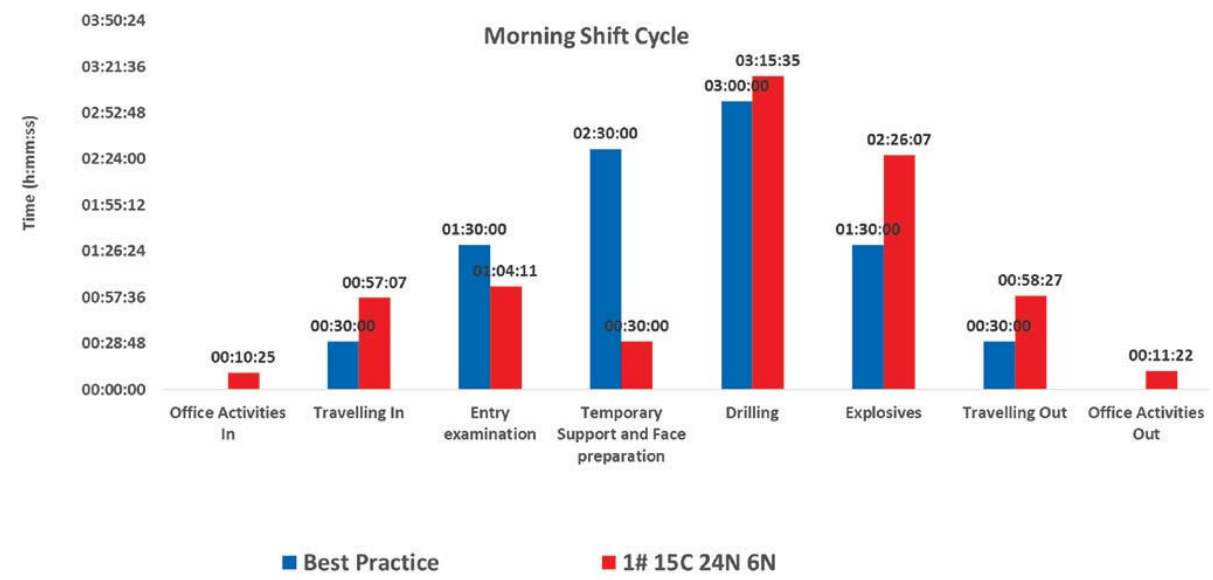

Figure 12-Morning shift activities for 15C 24N 6N 1\#

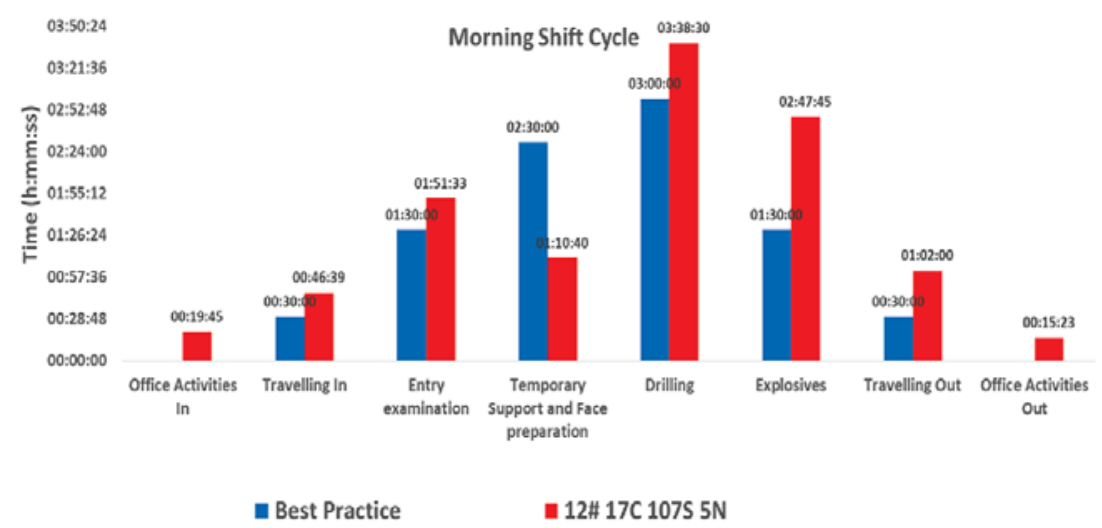

Figure 13-Morning shift activities for 17C 107S 12\# 